\title{
Evaluation of CR-39 Track Parameters by Utilizing Chemical Organic Additives to NaOH Etchant
}

\author{
Habib M. N. ${ }^{1}$, Abo-Elmagd M. ${ }^{2}$, Abd El-Hafez A. I. ${ }^{2}$, El-Faramawy N. A. ${ }^{1}$ \\ ${ }^{I}$ Physics Department, Faculty of Science, Ain Shams University,11566 Abbassia Cairo, Egypt \\ ${ }^{2}$ Ionizing Radiation Metrology Laboratory (IRML), National Institute for Standards (NIS), Giza, \\ Egypt.
}

Corresponding author email:nis_arafa@yahoo.com

Received on: 8 April 2021; Accepted on: 26 June 2021

\begin{abstract}
The nuclear track detector, CR-39, is widely used for detecting Alpha-particles which produce latent tracks on it and can be enlarged by using a suitable chemical etchant to be visible under an optical microscope. The commonly used etchant is an aqueous $6.25 \mathrm{~N}$ solution of $\mathrm{NaOH}$ at $70^{\circ} \mathrm{C}$. The behavior of the track parameters were studied at different etching times using direct measurements of the track opening diameters. These parameters were re-evaluated after adding some organic solution to the Sodium Hydroxide etchant to improve the etching conditions and so the quality of the tracks. These parameters including the track density, track diameter, the bulk, and the track etch rates, as well as track length, and depth. It has been found that Methanol and Ethanol additives led to a decrease of the bulk and track etch rates but with about 30\% increasing of the track etch rate ratio compared with their values in case of using $\mathrm{NaOH}$ without any additives. In the case of using Benzene and Acetone additives, there is no remarkable changes in these parameters. On the other hand, the etching efficiency was increasing more than the double in case of Methanol and Ethanol and decreasing near the half in case of benzene and acetone.
\end{abstract}

Keywords: CR-39 Detector, Chemical Etching; New Etchant; Track Etching Parameters

\section{Introduction}

\section{$1.1 C R-39$}

Heavy charged particles can leave latent quasi-continuous trails of damage in dielectric media, which are relatively long-lived at normal temperature. Different dielectrics have different 'registration thresholds', such that only those particles which have linear rates of energy loss, above a critical value, will be registered in a given dielectric medium. These polymers have far lower registration thresholds than glasses and mineral crystals, and can therefore often record tracks of such low atomic numbers as alpha particles.

The net effect of the energy loss is the production of bond rupture to form a complex array of free radicals, ionized molecules and radical ions along the track of 
heavy ion. These broken molecular chains reduce the molecular weight of the detector substance which increases the rate of a chemical attack on the detector. Subsequently, the area of the broken molecular chain (scission) is dissolved, and the resulting hole can become enlarged by factors of $10^{2}$ to $10^{3}$.

Solid-state nuclear track detectors (SSNTDs) have been successfully employed in different applications in science and technology [1], including in alpha autoradiography [2], radiation dosimetry [3] and particle identification [4].

Among SSNTD, polycarbonate has the advantage that it can reveal tracks of low energies within the limit of the alpha energies. Among polycarbonate, Polyallyldiglycol carbonate with molecular formula $\mathrm{C}_{12} \mathrm{H}_{18} \mathrm{O}_{7}$ is one of the most sensitive materials for recording alpha particles. These materials are commonly referred to as CR-39. Actually, CR is a registered trademark referring to Colombia Resin \#39, products of Pittsburgh Plate Glass Company. The most important features of CR-39 are its sensitivity, stability and the uniformity also it has an important feature that it can alter its response within limits by suitable choice of etching condition. CR-39 is used extensively to give data in a different field such as Brachytherapy [5], Boron Neutron Capture Therapy BNCT [6-7], U-exploration Galleries [8-9], and measurements of Radon in building materials [10].

\subsection{Track Geometry and Profile.}

The damaged region resulting from the passage of a heavy ion through SSNTD will be chemically more reagent than the surrounding undamaged matter. This damaged region is attacked by a higher rate if it is treated with a properly chosen chemical reagent.

There are two kinds of etching rates that are the bulk etching rate for the undamaged material $V_{B}$ and the track etching rate $V_{T}$ for the damaged one, where the etching solution penetrates along the latent track. $V_{B}$ and $V_{T}$ are sufficient to describe the etched track where the simultaneous action of them can create a cone that has the original track as its axis. A result of competition between the effect of $V_{B}$ and $V_{T}$ is the visible track depth $\mathrm{L}_{\text {depth }}$ and track diameter $\mathrm{D}$ as shown in Figure (1).

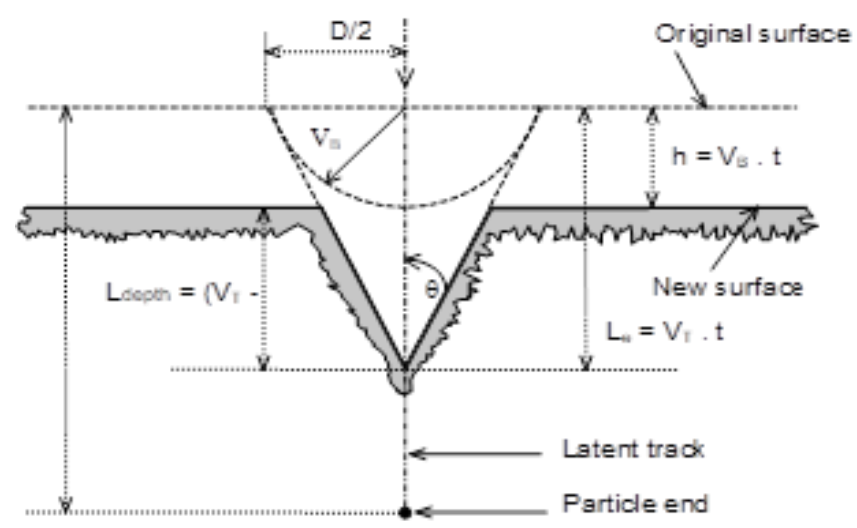

Fig.1. The etched track profile and its parameters at constant VT for a particle lying normal to the detector surface.

$V_{T}$ must be exceed $V_{B}$ to get a visible track, where the smaller the excess of $V_{T}$ over $\mathrm{V}_{\mathrm{B}}$ the larger the cone angle $\theta\left(=\arcsin \mathrm{V}_{\mathrm{B}} / \mathrm{V}_{\mathrm{T}}\right)$.

The bulk etch rate $V_{B}$ is calculated using the following equation:

$$
\mathrm{V}_{\mathrm{B}}(\mathrm{h})=\Delta \mathrm{h} / 2 \Delta \mathrm{t}
$$

Where $\Delta \mathrm{h}$ is the layer removed during the etching time $\Delta \mathrm{t}[(11]$. 
The diameter etch rate $\mathrm{V}_{\mathrm{D}}$ is calculated by measuring the diameter of alpha tracks at different etching times; then calculated by using the following equation:

$$
\mathrm{V}_{\mathrm{D}}=\Delta \mathrm{D} / \Delta \mathrm{t}
$$

The track etching rate $V_{T}$ was calculated using the following equations [12]:

$$
V_{T}=V_{B} \frac{4 V_{B}^{2}+V_{D}^{2}}{4 V_{B}^{2}-V_{D}^{2}}
$$

There are many parameters used to describe the geometry of etched track, these are

- The full length of the latent track (L).

- The thickness of the surface removed by etching (h).

- The diameter of the etch pit (D).

The track length (Le) at etching time $(t)$ is given by the following relation.

$$
\mathrm{Le}=\mathrm{V}_{\mathrm{T}} \mathrm{t}
$$

The surface is also begun removed at a rate $V_{B}$ so that the track depth is given by the following relation [13]

$$
\mathrm{L}_{\text {depth }}=\mathrm{V}_{\mathrm{T}} \mathrm{t}-\mathrm{V}_{\mathrm{B}} \mathrm{t}
$$

The etching efficiency $(\eta)$ is defined as the ratio of the counted tracks and the number of particles incident on the detector surface, the efficiency depends on the track etched rate $\mathrm{V}_{\mathrm{T}}$ and the bulk etched rate $\mathrm{VB}$ as follows:

$$
\eta=1-\frac{V_{B}}{V_{T}}
$$

The main objective of this paper is to improve the condition of track formation on CR-39 by using different additive to the etching solution and study different track etching parameters, including $\mathrm{V}_{\mathrm{B}}, \mathrm{V}_{\mathrm{T}}$, Le, $\mathrm{L}_{\text {depth }}$ and $\eta$.

\section{Method Methodology}

\subsection{Radiation exposures of CR-39 detectors}

CR-39 detector sheet of thickness $700 \mu \mathrm{m}$, manufactured by American Acrylics (US), was cut by laser beam into pieces of area $1 \times 1 \mathrm{~cm}^{2}$. CR-39 detectors were preserved in special plastic envelopes. All samples were exposed to ${ }^{241} \mathrm{Am}$ source (activity was $0.106 \mu \mathrm{Ci}$ and main alpha energy was $5.49 \mathrm{MeV}$ ). A collimator was used such that the incident alpha particles have energy of $3 \mathrm{MeV}$ and $90^{\circ}$ incident angle in air.

\subsection{Chemical etching of CR-39 detectors}

Immediately after irradiation, the detectors were etched in a $6.25 \mathrm{~N}$ aqueous solution of $\mathrm{NaOH}$ at different etching times equal to $2,4,5$ to $8 \mathrm{~h}$ maintained at temperature of $70{ }^{\circ} \mathrm{C}$ in a water bath. The optimum etching time must be short enough to avoid over etched tracks [14]. The detectors were then taken out from the etchant, rinsed with distilled water, and dried. CR-39 detectors were then counted by an optical microscope to determine the track density in terms of tracks per $\mathrm{cm}^{2}$. The background track density was determined by processing a virgin detector under the same etching conditions, and then the background was subtracted from the measured track density, to obtain realistic statistics of the tracks.

The other part of this work is the use of different solutions such as ethanol, methanol, benzene, and acetone mixed with sodium hydroxide solution and etched at the same optimum etching conditions. 


\section{Results and Discussion}

\subsection{The track parameters for $\mathrm{NaOH}$ etchant}

Figure (2) shows the relation between the track densities at different etching time where the maximum track density is obtained around 6 hours etching times.

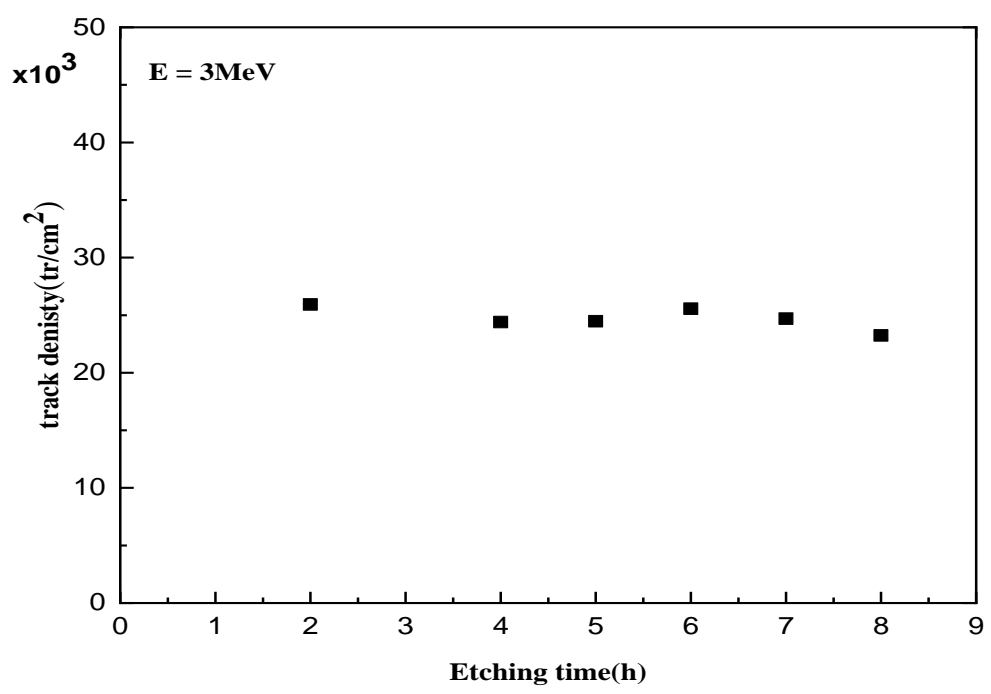

Fig. 2. The track density at different etching times at $6.25 \mathrm{~N} \mathrm{NaOH}$ and $70^{\circ} \mathrm{C}$.

The track diameter is increasing with etching time as shown in Figure (3) where the relationship is close to the linear form. At etching time more than 6 hours, the increasing of the track diameter is responsible for the decreasing of the track density due to the tracks overlapping.

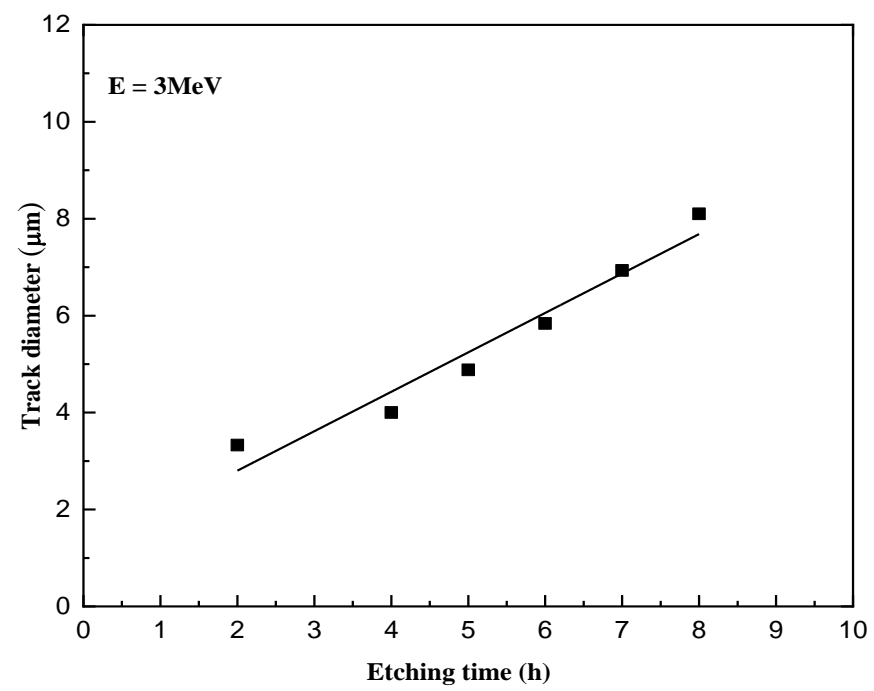

Fig. 3. Relation between the track diameter and the etching time at $6.25 \mathrm{~N} \mathrm{NaOH}$ and $70^{\circ} \mathrm{C}$.

The response of CR-39 is shown in Figure (4) as a relation between the fluence of the incident Alpha-particles and the registered track density. The relation is linear with a correlation coefficient equal to 0.99 . The slope of the given line is equal to 
$0.36 \pm 0.02 \mathrm{~T} / \alpha$ which is the response of the CR-39 detector for $3 \mathrm{MeV}$ normal incident Alpha particles.

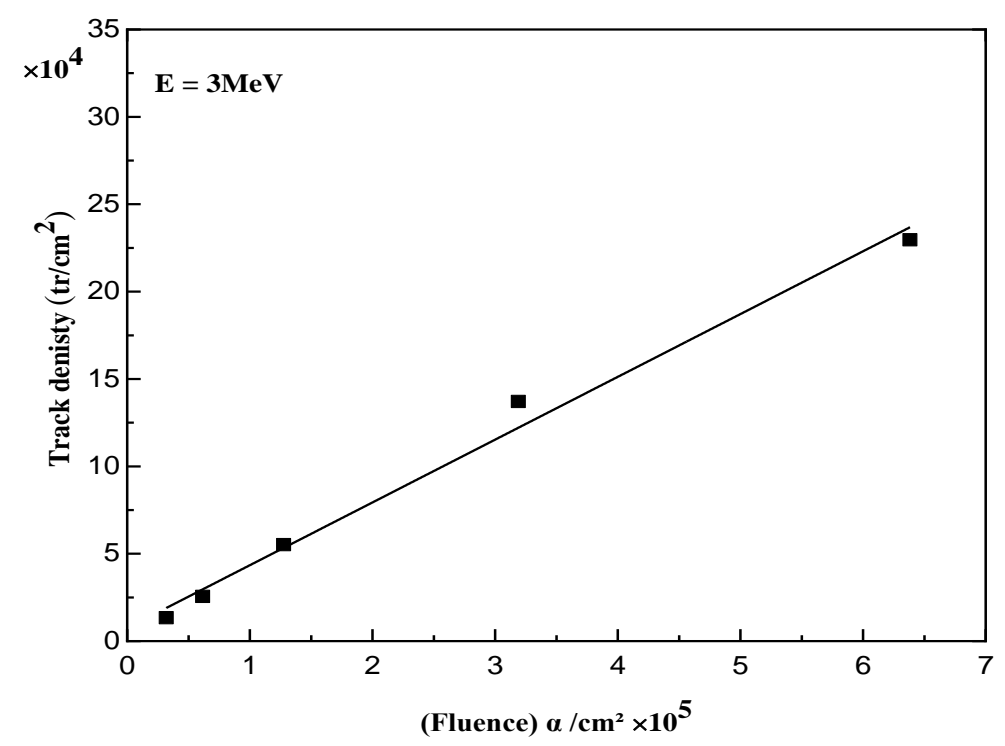

Fig. 4. Relation between the fluence of alpha particles and the track density at the optimum etching condition of $6.25 \mathrm{~N} \mathrm{NaOH}$ at $70^{\circ} \mathrm{C}$ for 6 hours.

After each etching time, the bulk etch rate $V_{B}$ was calculated by measuring the removed layer $\Delta \mathrm{h}$ and use Equation (1), the mean value of $\mathrm{V}_{B}$ is equal to $1.89 \mu \mathrm{m} / \mathrm{h}$ which was shown as a horizontal line in Figure (5). The bulk etches rate $V_{B}$ was measured to be $1.67 \mu \mathrm{m} / \mathrm{h}$ under the circumstances of $6.25 \mathrm{~N} \mathrm{NaOH}$ at $70^{\circ} \mathrm{C}$ for $6 \mathrm{~h}$. This value as well as the average one is higher than that obtained by Ibrahim and Wathab, [15] who obtained a value of $1.29 \mu \mathrm{m} / \mathrm{h}$ using $6 \mathrm{~N} \mathrm{NaOH}$. Also, Najeba et al., [16] measured $V_{B}$ as $1.174 \mu \mathrm{m} / \mathrm{h}$, and Matiullah et al., [17] measured $\mathrm{V}_{B}$ as 1.25 $\mu \mathrm{m} / \mathrm{h}$.

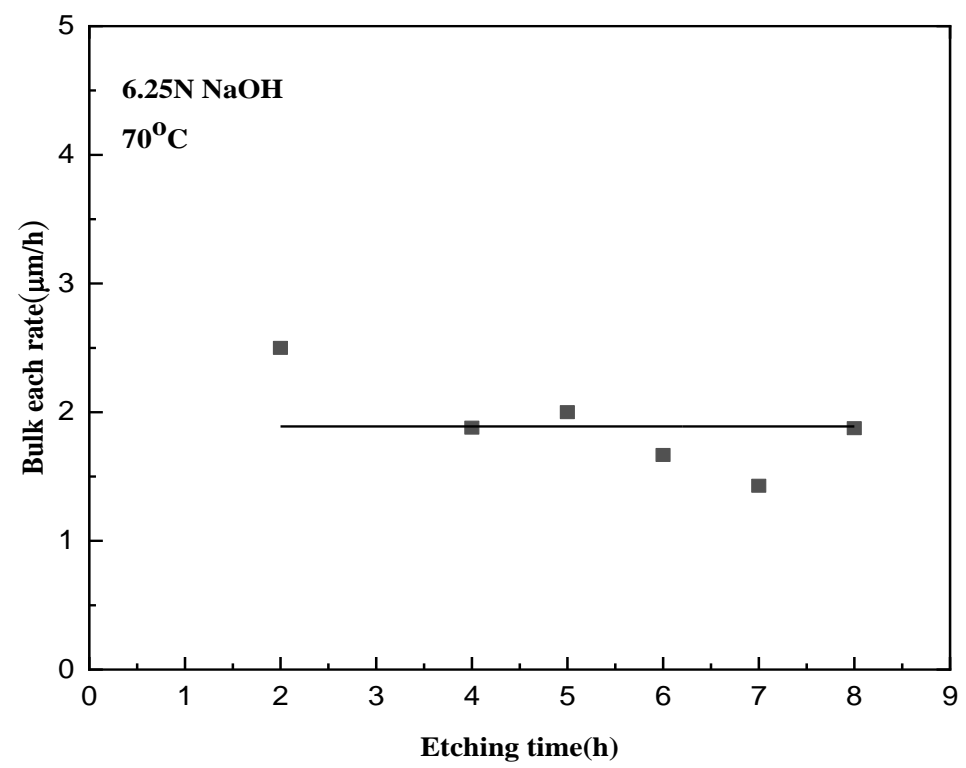

Fig. 5. The bulk each rate at different etching time. 
Figure (6) shows the track etch rate determined from Equation (3) for different etching times ranging from 4 to 8 hours. The Figure shows that the track etch rate increases with time, peaking at around 5 hours etching time before declining. After 5 hours of etching, the decayed values of $\mathrm{V}_{\mathrm{T}}$ are expected to hit their minimum value, which is equal to $V_{B}$. For $6 \mathrm{~h}$ etching time, The track etch rate is equal to $1.98 \mu \mathrm{m} / \mathrm{h}$ which consistent with the work of Ansari et al., [18] who found that $\mathrm{V}_{\mathrm{T}}$ is ranged from 1.88 to $2.0 \mu \mathrm{m} / \mathrm{h}$, for different manufactured CR-39 sheets with the same etching condition of $6 \mathrm{~N} \mathrm{NaOH}$ at $70{ }^{\circ} \mathrm{C}$.

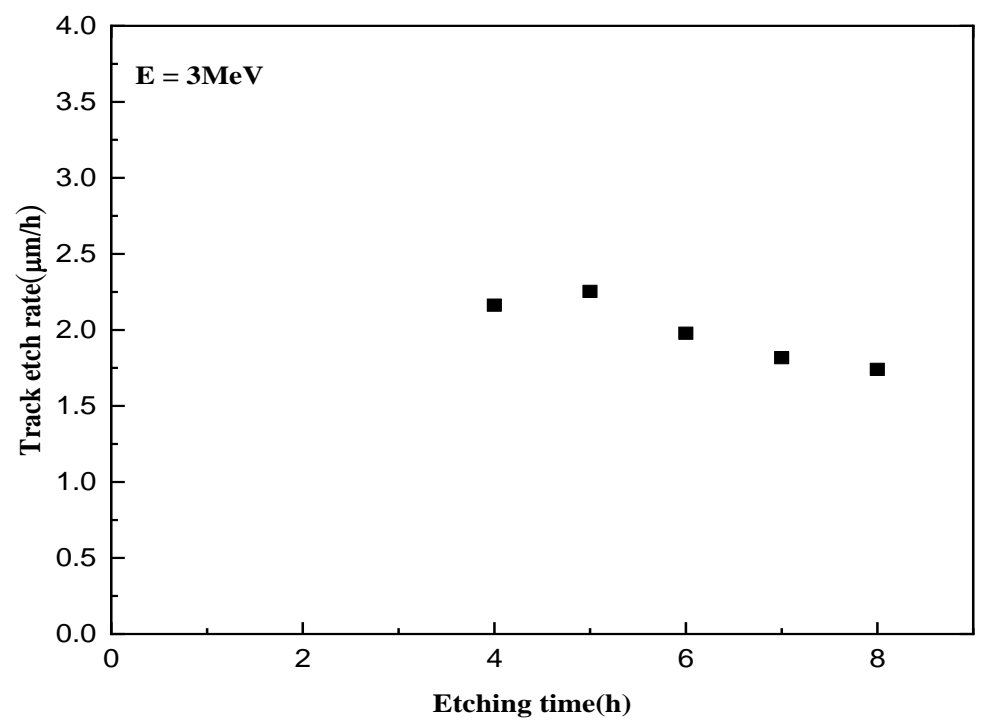

Fig. 6. Relation between the track etch rate and the etching time at $6.25 \mathrm{~N} \mathrm{NaOH}$ and $70^{\circ} \mathrm{C}$.

Also, the behavior of the track etches rate ratio $\mathrm{V}$ (which is the ratio between $\mathrm{V}_{\mathrm{B}}$ and $\mathrm{V}_{\mathrm{T}}$ ) was found to be similar to that of $\mathrm{V}_{\mathrm{T}}$ as shown in Figure (7). At $6 \mathrm{~h}$ etching time, $\mathrm{V}$ is equal to 1.19 and tends to reach 1 at the etching time higher than 8 hours.

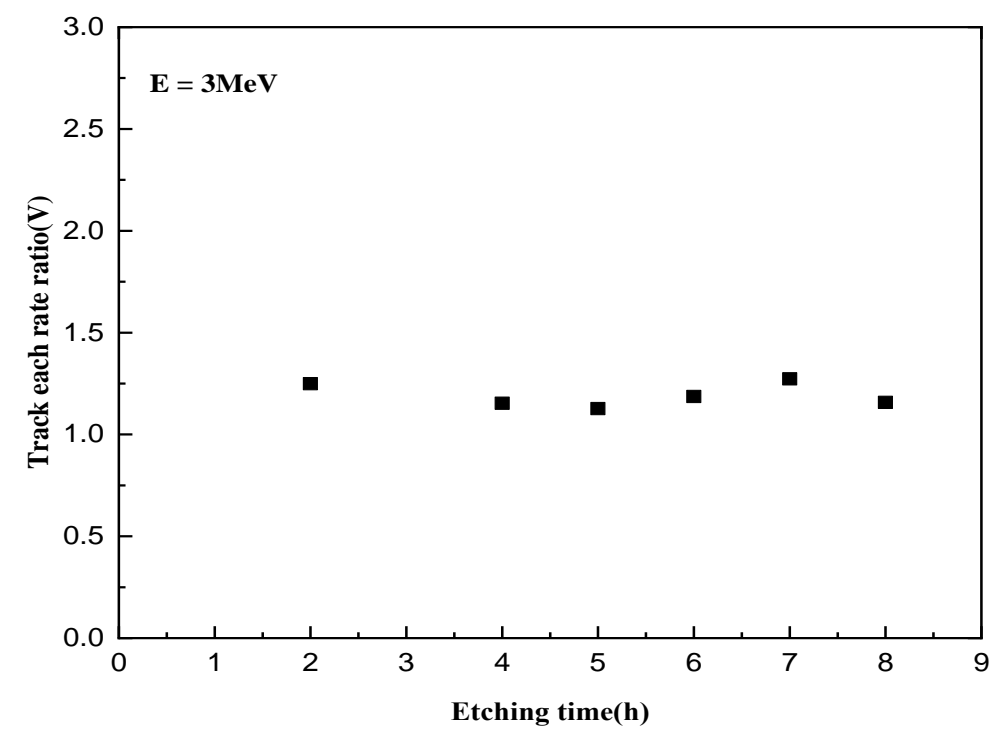

Fig. 7. Relation between the track etch rate ratio and the etching time at $6.25 \mathrm{~N}$ $\mathrm{NaOH}$ and $70^{\circ} \mathrm{C}$. 
The track depth and the track length as a function of etching time are shown in Figures $(8,9)$. It can be observed that the track depth increases with the etching time up to a maximum constant value at the end of the track. Noting that the track length increases gradually with etching time leading to the maximum value at the end of the path of a particle in the detector, or the greatest absorption of energy, Figure (8).

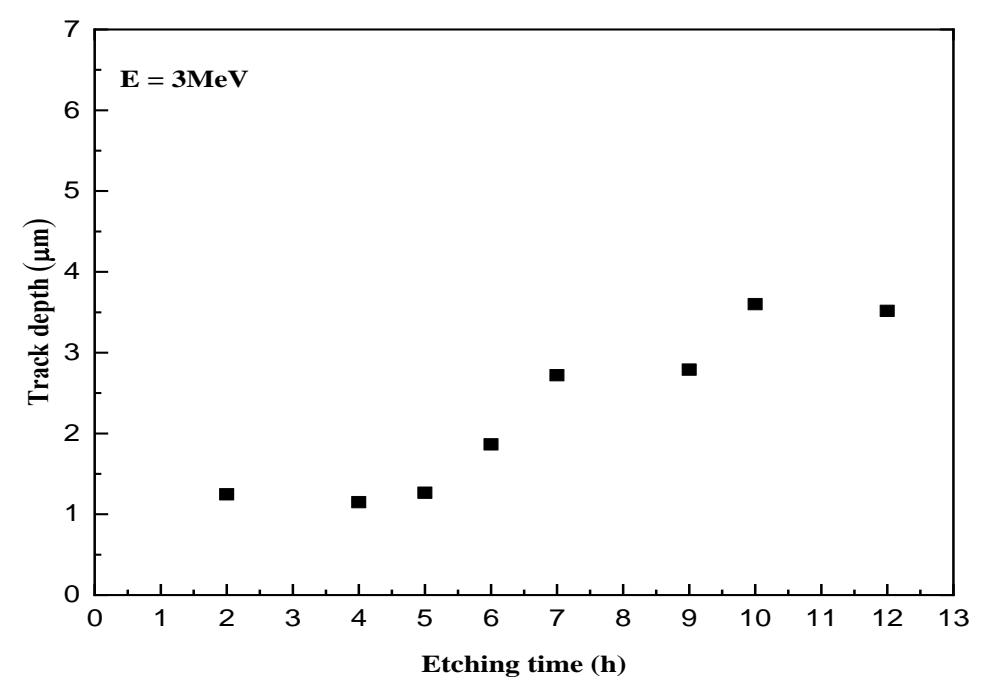

Fig. 8. Relation between the track depth and the etching time at $6.25 \mathrm{~N} \mathrm{NaOH}$ and $70^{\circ} \mathrm{C}$.

The tracks lengths were plotted as a function of etching time in Figure (9). The track lengths are not linearly changing with etching time, they are growing gradually up to a maximum value and then access to constant values when the etching solution crossing the region under the end of the particle range in the detector. With the continued etching process, $\mathrm{V}_{\mathrm{T}}$ decreases and drops sharply so that it equals the bulk etch rate $\left(V_{B}\right)$, and then the etching ratio $(V)$ ends to one $(V=1)$ after the etchant completely reaches the end of the particle range. Applying the limited condition is that when the etching solution reaches the end of the incident particle range, further prolongation of the etching time does not result in the further growth of the track length because the etching now takes place with the bulk etch rate in all directions and this appears at etching times more than 8 hours.

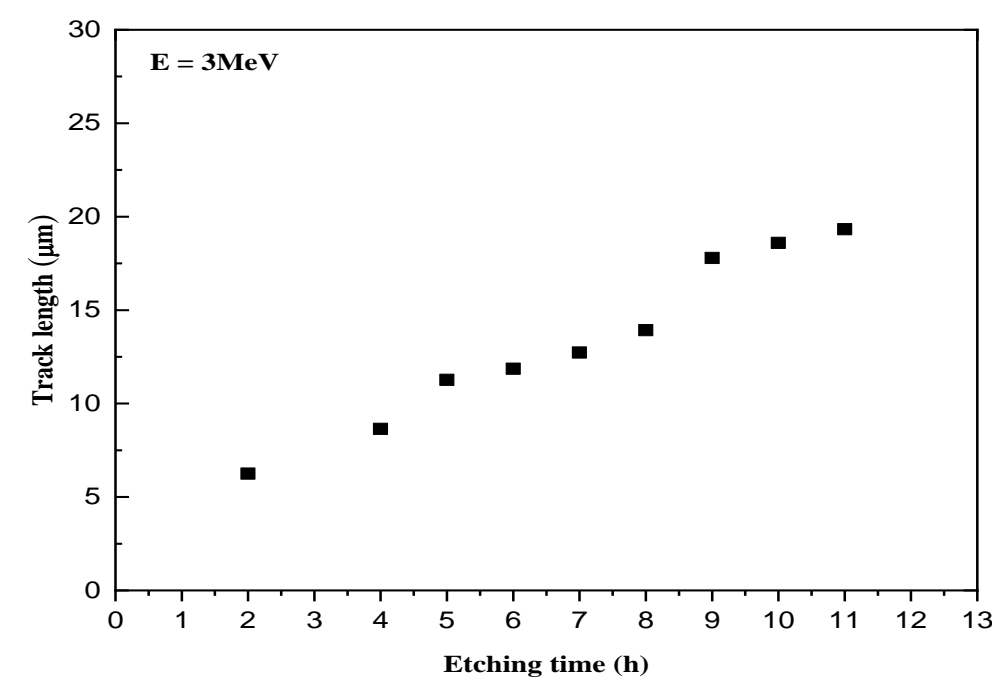

Fig. 9. Relation between the track length and the etching time at $6.25 \mathrm{~N} \mathrm{NaOH}$ and $70^{\circ} \mathrm{C}$. 
Figure (10) shows the efficiency as a function of etching time, which was calculated from the track parameters as given in Equation (6). At 6 hours of etching time, the efficiency is 0.16 . The etching efficiency increases slightly with etching time, reaching a maximum of 0.28 after 8 hours, then dropping to a minimum of about 0.11 after 12 hours etching time.

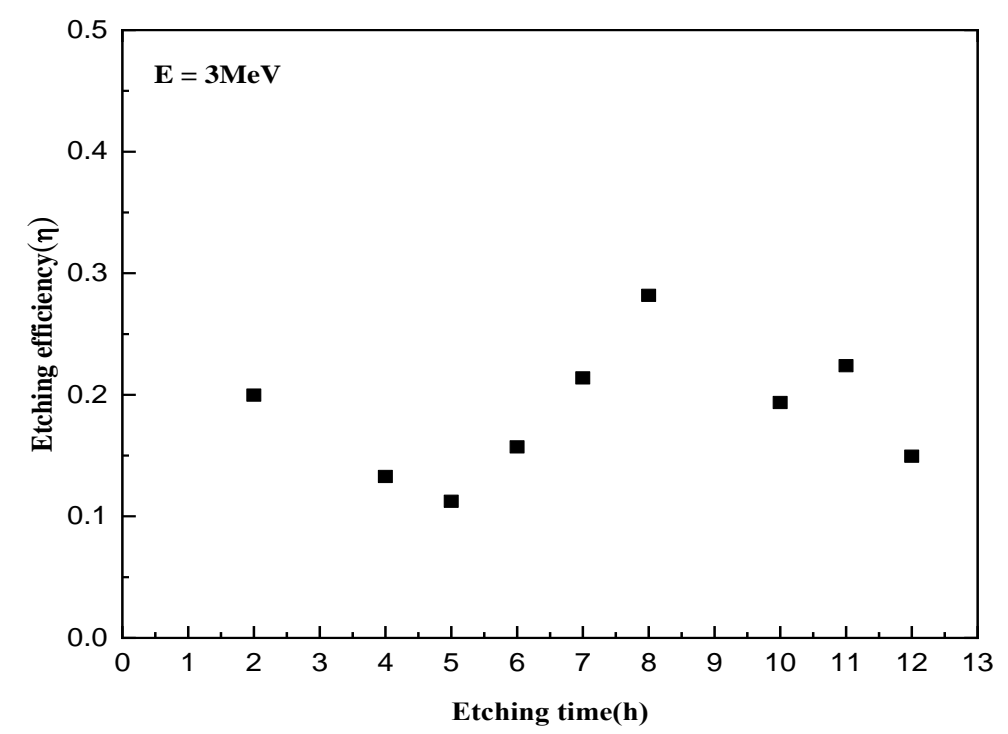

Fig. 10. The etching efficiency as a function of the etching time at $6.25 \mathrm{~N} \mathrm{NaOH}$ and $70^{\circ} \mathrm{C}$.

\subsection{The track parameters using different etchant additives}

After adding $1 \mathrm{ml}$ of Ethanol, Methanol, Benzene, or Acetone to $6.25 \mathrm{~N} \mathrm{NaOH}$ solutions using an etching time of $6 \mathrm{~h}$ at $70^{\circ} \mathrm{C}$, the track parameter were re-evaluated and compared to that obtained at the optimum etching condition using $\mathrm{NaOH}$ without any additives.

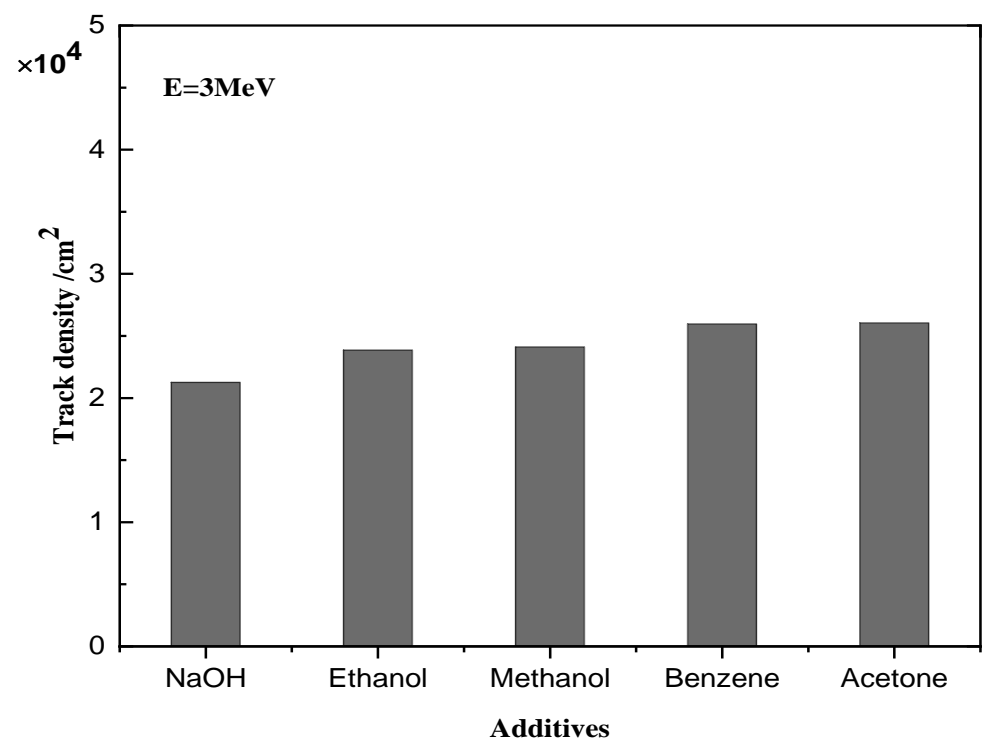

Fig. 11. The track density using $1 \mathrm{ml}$ of different additives to $6.25 \mathrm{~N} \mathrm{NaOH}$ solution at $70^{\circ} \mathrm{C}$ for 6 hours etching time. 
Figure (11) shows the track density for CR-39 using these additives compared with $\mathrm{NaOH}$ without any additives. The Figure indicates a slight increase in the track density, especially for Benzene and Acetone. Otherwise, the track diameters are decreasing with using these additives as shown in Figure (12).

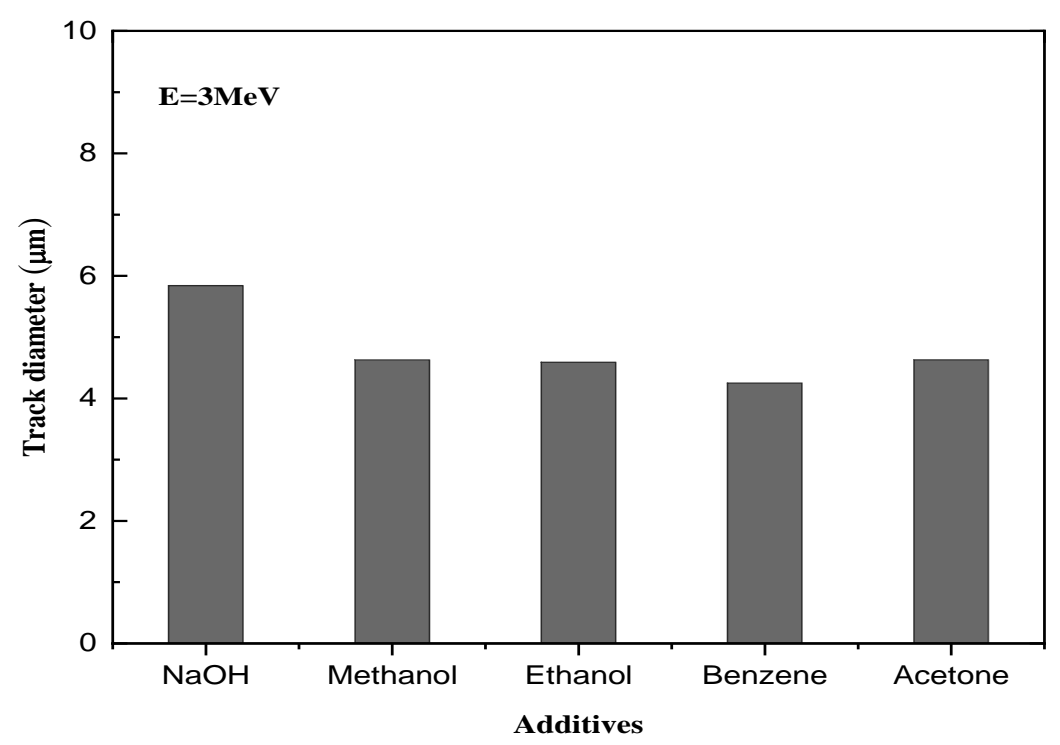

Fig. 12. The track diameters using $1 \mathrm{ml}$ of different additives to $6.25 \mathrm{~N} \mathrm{NaOH}$ solutions at $70^{\circ} \mathrm{C}$ for 6 hours etching time.

The bulk etches rate $V_{B}$ was re-evaluated after adding the different organic solutions. The additives of methanol and ethanol displayed a decrease in the value of $\mathrm{V}_{\mathrm{B}}$ with about $50 \%$ (a value of $0.83 \mu \mathrm{m} / \mathrm{h}$ ) while $\mathrm{V}_{B}$ remains unchanged for benzene and acetone (Table 1). For ethanol, Vivek et al., [19] varied the normality from 1.5 up to 3 with an increment of 0.5 and found that the values of $V_{B}$ changed to 3.0, 3.99, 5.32, and $11.6 \mu \mathrm{m} / \mathrm{h}$. When Ibrahim and Wathab, [15] changed the additive to be methanol with normality values of $1.5,2,2.5$, and 3 , the values of $V_{B}$ were increased dramatically to be $3.009,3.99,5.32$, and $7.38 \mu \mathrm{m} / \mathrm{h}$. While Ashry et al., [20] measured $\mathrm{V}_{\mathrm{B}}$ under different conditions $\left(10 \mathrm{~N} \mathrm{NaOH}+\right.$ methanol, $50-70^{\circ} \mathrm{C}$, and 45 min etching time) to be $2.73 \mu \mathrm{m} / \mathrm{h}$. It can be deduced from the current and previous research that the bulk etch rate is highly affected by the additives and concentration of the etching solution.

It was observed that the track etch rate $\mathrm{V}_{\mathrm{T}}$ decreased about $35 \%$ after adding ethanol solution $(1.28 \pm 0.39) \mu \mathrm{m} / \mathrm{h}$ and methanol solution $(1.29 \pm 0.39) \mu \mathrm{m} / \mathrm{h}$. For benzene and acetone, $\mathrm{V}_{\mathrm{T}}$ is slightly decreasing (about $8 \%$ ) to give values equal to $(1.82 \pm$ $0.0071) \mu \mathrm{m} / \mathrm{h}$ and $(1.86 \pm 0.014) \mu \mathrm{m} / \mathrm{h}$ respectively (Table 1$)$.

After adding organic solutions, the values of $\mathrm{V}$ were changed as shown in Table (1) from 1.19 (in the case of $\mathrm{NaOH}$ solution) to reach $1.09,1.11,1.53$, and 1.55 for benzene, acetone, ethanol, and methanol respectively as listed in the Table (1). These results revealed that the tracks etch rate ratio $(\mathrm{V})$ increases for methanol and ethanol by about $30 \%$ and slightly decreases in the case of benzene and acetone. 
Table 1. The measured track parameters for different organic additives to $6.25 \mathrm{~N} \mathrm{NaOH}$.

\begin{tabular}{l|c|c|c|c|c|c|c}
\hline Additives & $\mathrm{V}_{\mathrm{B}}$ & $\mathrm{V}_{\mathrm{T}}$ & $\mathrm{V}$ & $\theta_{\mathrm{c}}$ & $\eta$ & $\mathrm{L}_{\text {depth }}{ }^{\prime}$ & $\mathrm{L}_{\mathrm{e}}$ \\
\hline $\mathrm{NaOH}$ & 1.67 & 1.98 & 1.19 & 57.44 & 0.16 & 1.86 & 11.86 \\
Methanol & 0.83 & 1.29 & 1.55 & 40.27 & 0.35 & 2.73 & 7.73 \\
Ethanol & 0.83 & 1.28 & 1.53 & 40.7 & 0.35 & 2.67 & 7.67 \\
Benzene & 1.67 & 1.82 & 1.09 & 65.98 & 0.09 & 0.95 & 10.95 \\
Acetone & 1.67 & 1.86 & 1.11 & 63.94 & 0.10 & 1.13 & 11.13 \\
\hline
\end{tabular}

After adding the organic solutions, the results of track depth and length were reassessed; it was found that the track depth was increased in the case of methanol and ethanol, in contrast to what happened with the benzene and the acetone which started to decrease less than that of using $\mathrm{NaOH}$ (Figure 13). The etchant attacks the damaged region regardless of the used additives. But where methanol and ethanol show a reduced effect on the bulk etch rate then the depth of the track seems to be larger than the case of $\mathrm{NaOH}$. Also, the bulk etch rate is larger in the case of benzene and acetone (equal to that of $\mathrm{NaOH}$ ), then the depth, in this case, seems to be smaller like that of $\mathrm{NaOH}$.

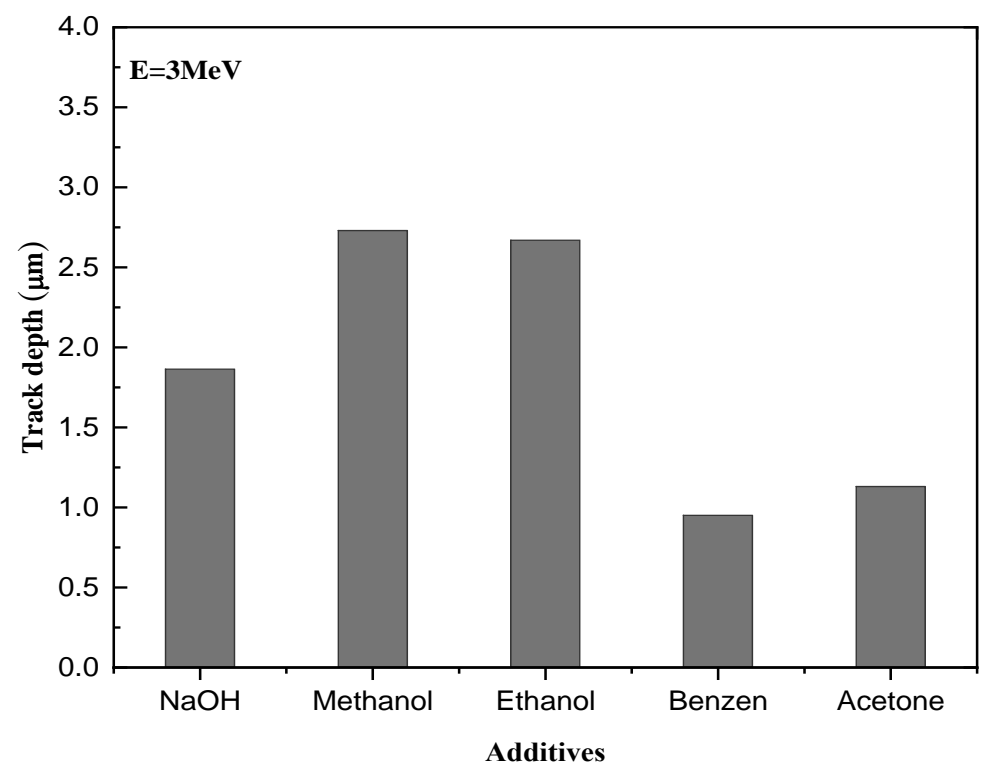

Fig. 13. The track depth using $1 \mathrm{ml}$ of different additives to $6.25 \mathrm{~N} \mathrm{NaOH}$ solutions at 70o $\mathrm{C}$ for 6 hours etching time.

But when determining the track length after adding the organic solutions, it was found that ethanol and methanol showed track lengths smaller than that of $\mathrm{NaOH}$, while benzene and acetone show larger track lengths but still less than $\mathrm{NaOH}$ (Figure 14). In this case, the track etch rate is the important parameter which is proportional to the track length and so has the same behaviour as shown in Table (1). 


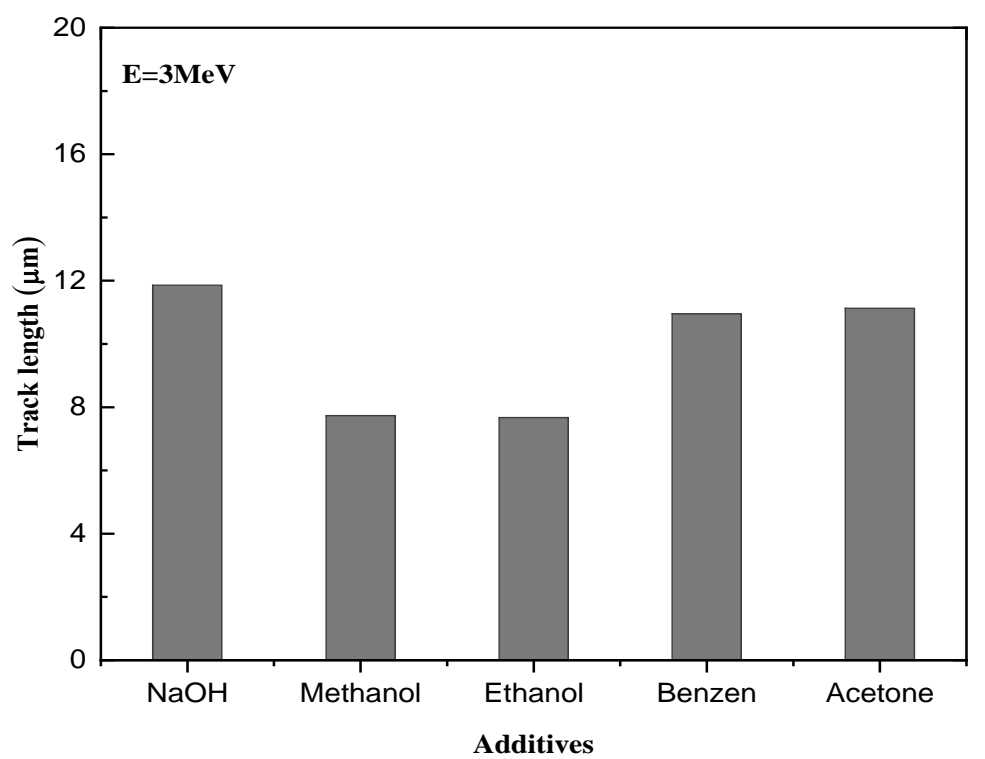

Fig. 14. The track length using $1 \mathrm{ml}$ of different additives to $6.25 \mathrm{~N} \mathrm{NaOH}$ solution at $70^{\circ} \mathrm{C}$ for 6 hours etching time.

The efficiency was re-evaluated after adding the used organic solutions. Comparing the results with that obtained for using $\mathrm{NaOH}$ without any additives, the efficiency was decreased $38 \%$ in the case of using benzene and acetone but increased more than twice (about $120 \%$ ) when using ethanol and methanol (Table 1) and Figure (15). This finding is a direct result of the combined effect of $V_{B}$ and $V_{T}$ as discussed before and this finally indicates some advantages of using ethanol and methanol as organic additives to the $\mathrm{NaOH}$ etchant.

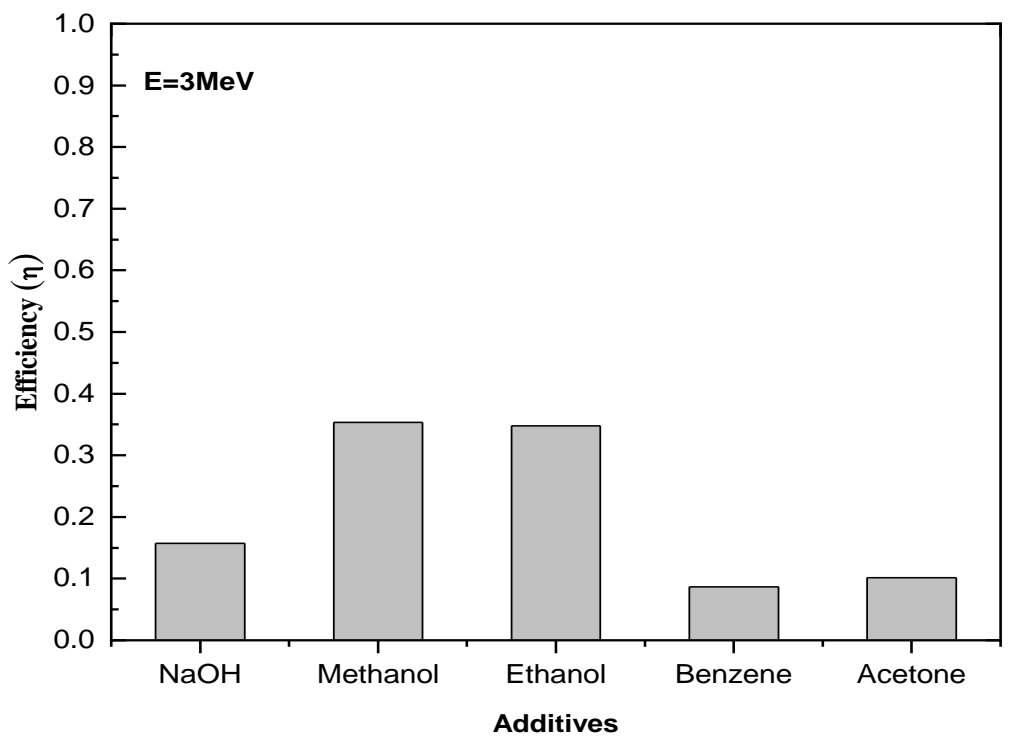

Fig. 15. The detector efficiency using $1 \mathrm{ml}$ of different additives to $6.25 \mathrm{~N} \mathrm{NaOH}$ solution at $70^{\circ} \mathrm{C}$ for 6 hours etching time. 


\section{Conclusion}

The track parameters of CR-39 were calculated for optimum condition of $6.25 \mathrm{~N}$ $\mathrm{NaOH}$ etchant at $70{ }^{\circ} \mathrm{C}$ at various etching times. The bulk etch rate $\mathrm{V}_{\mathrm{B}}$ and the diameter etch rate $V_{D}$ are critical parameters, and accurate measurements of these parameters allow for the proper estimation of residual parameters like the track etch rate $V_{T}$, the track etch rate ratio $V$, the detector etching efficiency $\eta$, and the track length and its depth.

The values of $\mathrm{V}_{\mathrm{B}}$ and $\mathrm{V}_{\mathrm{T}}$ obtained at the optimum etching time of 6 hours are compatible with those obtained by several authors. The estimated etching efficiencies obtained from measured track parameters at various etching times have a maximum value of about 0.28 , which is lower than the value obtained from direct measurement of track densities at various Alpha-particle fluencies under the optimum etching time (about 0.35).

When the organic solvent is added to the $\mathrm{NaOH}$ etchant, the determined parameters are affected differently according to the used additives. The effects of methanol and ethanol additives on $\mathrm{V}_{\mathrm{T}}, \mathrm{V}_{\mathrm{B}}, \mathrm{V}$, and $\eta$ are significant. As compared to $\mathrm{NaOH}$ without additives, the etchant attacks the bulk of the detector twice as quickly. As a consequence, the length of the track is shortened while the depth is increased. As a result of these additives, the etching condition is improved, resulting in higher detector efficiency.

\section{References}

1. Price P. B. Recent applications of nuclear tracks in solids, Radiat. Meas., Vol. 43, p. 513-525, (2008).

2. Kodaira S., Morokoshi Y., Li H. K., Konishi T., Kurano M. and Hasegawa S. Evidence of Local Concentration of $\alpha$-Particles from ${ }^{211}$ At-Labeled Antibodies in Liver Metastasis Tissue, Journal of Nuclear Medicine, Vol. 60 (4), p. 497-501, (2019).

3. Doke T., Hayashi T., Nagaoka S. h., Ogura T. K. and Takeuchi R. Estimation of Dose Equivalent In Sts-47 By A Combination of TLDs And CR-39, Radiation Measurements, Vol. 24 (1), p. 75-82, (1995).

4. Bartz J. A., Kodaira S., Kurano M., et al. High resolution charge spectroscopy of heavy ions with FNTD technology, Nucl. Instr. Meth B, Vol. (335), p. 24-30, (2014).

5. Abd El-Hafez A. I., Eissa H. M., Eman S. A. and Fadel M. A. Inter comparative studies of brachytherapy techniques combined with $\mathrm{Cf}$ boron neutron capture therapy, Radiat. Meas., Vol. 28, p. 435-440, (1997).

6. Smilgys B., Guedes S., Morales M., Alvarez F., Hadler J. C., Coelho P. R. P., Squeira P. T. D., Alencar I., Soares C. J. and Curvo E. A. C., Boron thin films and CR-39 detectors in BNCT: a method to measure the 10B $(\mathrm{n}, \alpha) 7 \mathrm{Li}$ reaction rate, Radiat. Meas., Vol. 50, p. 181-186, (2013).

7. Abd El-Hafez A. I., Eissa H. M., Eman S. A. and Fadel M. A. Measurement of dose enhancement by neutron capture of boron in Cf interstitial brachytherapy, Radiat. Meas. Vol. 28, p. 441-444, (1997).

8. Abd El-Hafez A. I., Abdel Monem A. A., Eissa H. M., El-Fiki S. A., Abdel-Razek Y. A. and El-Naggar, A. M. The Evaluation of Radon Concentration and Radon 
Decay Products Concentrations Using SSNTD in J-Exploration Galleries in the Eastern Desert, Egypt, Egypt J Phys., Vol. 29, p. 235-249, (1998).

9. Abd El-Hafez A. I., Abdel-Monem A.A., Eissa H. M., El-Fiki S. A., Abdel-Razek Y. A. and El-Naggar A. M. Measurements of radon decay products and working level by active techniques in U-exploration galleries, Eastern Desert, Egypt, Egyp J Biophys, Vol. 5, p. 1-14, (1999).

10. Diab H. M. and Abd El-Hafez A. I. Reduction of Ambient Radon Activity by the Use of Advanced Building Materials at King Saud University, Saudi Arabia, Isot. Radiat., Vol. 43, p. 1177-1183, (2011).

11. Kalsi P. C., Sawant P. D., Ramaswami A. and Manchanda V. K. Track etching characteristics of polyester track detector and its application to uranium estimation in seawater samples, Journal of Radioanalytical and Nuclear Chemistry, Vol. 273(2), p. 473-477, (2007).

12. Nikezic D. and Yu K. N. Formation and growth of tracks in nuclear track materials, Mater. Sci. Eng. R: Reports 46, p. 51-123, (2004).

13. Al-Jubbori M.A., Azooz A.A. and Al-Nia'emi S.H. A parameterization of nuclear track profiles in CR-39 detector, Computer Physics Communications, Vol. 183, p. 2470-2479, (2012).

14. Caresana M., Ferrarini M., Fuerstner M., Mayer S. Determination of LET in PADC detectors through the measurement of track parameters, Nuclear Instruments and Methods in Physics Research A, Vol. 68, p. 8-15, (2012).

15. Ibrahim A. A. and Wathab H. Y. Effect of Etching Solution on Nuclear Track Detector CR-39, Int J Applied Eng. Res., Vol. 13, p. 8659-8663, (2018).

16. Najeba F. S., Mohamad S. and Jaafar. The optimum time of etching proved the Sensitivity of the CR-39 detector. Int. J. Sci. Eng. Res., Vol. 3(9), p. 1-8, (2012).

17. Matiullah R.S., Rehman S., Rehman S., Mati N. and Ahmad S. Some more new etchants for CR-39 detector, Radiat. Meas. Vol. 39, p. 551-555, (2005).

18. Ansari F., Matiullah, Javaid N. A., Khan E. U. and Fujii M. Etching characteristics and sensitivities of various commercially available CR-39 and Sr86 detectors, Nucl Tracks Radiat. Meas., Vol. 19, p. 139-142, (1991).

19.Vivek C., Kalsi P. C. and Manchanda V. K. A novel room temperature -induced chemical etching (RTCE) technique for the enlargement of fission tracks in Lexan polycarbonate SSNTD, Nucl. Instrum. Meth. A, Vol. 629, p. 145-148, (2011).

20. Ashry A. H., Abdalla A. M., Rammah Y. S., Eisa M. and Ashraf O. The use of $\mathrm{CH}_{3} \mathrm{OH}$ additive to $\mathrm{NaOH}$ for etching alpha particle tracks in a CR-39 plastic nuclear track detector, Radiat. Phys. Chem., Vol. 101, p. 41-45, (2014). 